\title{
How electric current stimulates the root formation of Salix cuttings
}

\author{
By Yasona FuKUDA* and Takeshi TAKAOKı*
}

福田八十楠, 高沖 武：柳の挿木の発根を促進させる電気の刺激過程について

\section{Received December 5, 1952}

The fact that the applied electric current accelerates the cataphoresis of hormone to the anode in agar-agar medium is affirmed $(11,4)$. In the living body, however, though the similar phenomenon is believed to have been affirmed by several authors $(2,21,12,11)$, it is denied also by other investigators $(7,9,3,5)$. By the applied E.M.F. the inherent potential may change $(2,13,11,4,14,10,15)$, and may indirectly influence growth $(17,10,16)$. Thimann and Went (19) succeeded in enlarging the potentiality of root formation of cuttings by putting them in heteroauxin solution. Watanabe and Ito (20) likewise found a way of accelerating the root formation of willow cuttings by electrifying them in the water tank. They thought that cataphoresis of charged auxin enlarged, resulting at the cut end, in the speedy accumulation of auxin which more strongly stimulated the root formation. The theories of the above investigators who continuously electrified materials, may not be adopted to the temporary electrifying of Watanabe and Ito. Electrifying effect on the cuttings of willow trees can be macroscopically observed in the plant itself, i.e the preparation is self-testable. Such suitable samples beeing presented, the authors repeated the test after Watanabe and Ito to study the way of stimulation of electric current on the root formation.

\section{MATERIAL AND METHODS}

It is a horticulturist's custom to prepare cuttings of willow trees before new shoots sprout, but Watanabe and Ito experimented electrifying on the root formation of willow trees after sprouting. So in this experiment the authors chose the similar period of the year. The former year's slender shoots, $8 \mathrm{~mm}$ in diameter, were taken from the willow trees, Salix babylonica L., and the shoots were cut $14.5-29.0 \mathrm{~cm}$

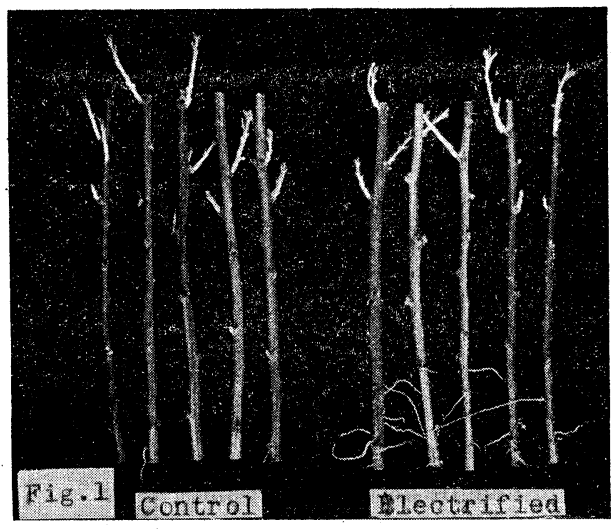

\footnotetext{
* The Botanical Institute, Faculty of Science, Hiroshima University. 広島大学理学部植物学教室
} 
long excluding tips with new sprouts. Five to ten shoots were bound together in the same polar direction, and placed in a glass cylinder of $5 \mathrm{~cm}$ in diameter and $30 \mathrm{~cm}$ in length, which was filled with water. As the electrodes two nickel gilted copper plates were attached to the top and bottom of the cylinder. During the latent period of root formation, the preparations were placed in a dark room, in order to prevent the disturbance of hormone distribution by the new hormone formation in the daylight. Observation was carried on 10-12 days after the electrifying. The presented values are the average of 5-10 examples.

\section{EXPERIMENTAL RESULTS}

A) Relation between the amount of applied E.M.F.s and the root formation. Watanabe and Ito (20) had found D.C. $50 \sim 200 \mathrm{~V}$ was the optimum voltage for this experiment, so the E.M.F. of the same voltage was again applied to the materials

\begin{tabular}{|c|c|c|c|c|c|c|}
\hline Treatment & Control & \multicolumn{5}{|c|}{$\begin{array}{l}\text { Applied potential } 100 \mathrm{~V}, 0.18 \sim 0.20 \mathrm{~mA} / \mathrm{cm}^{2} \text {, } \\
\text { anode at the base of cuttings }\end{array}$} \\
\hline Time of stimulus & $\begin{array}{l}0 \text { sec. } \\
\text { (ratio) }\end{array}$ & $\begin{array}{l}1 \mathrm{sec} . \\
\text { (ratio) }\end{array}$ & $\begin{array}{l}10 \mathrm{sec} . \\
\text { (ratio) }\end{array}$ & $\begin{array}{l}30 \mathrm{sec} \\
\text { (ratio) }\end{array}$ & (ratio) & $\begin{array}{l}3 \text { min. } \\
\text { (ratio) }\end{array}$ \\
\hline Number of new roots & $\begin{array}{l}1.0 \\
(100)\end{array}$ & $\begin{array}{c}1.9 \\
(190)\end{array}$ & $\begin{array}{c}2.7 \\
(270)\end{array}$ & $\begin{array}{c}1.8 \\
(180)\end{array}$ & $\begin{array}{c}3.1 \\
(310)\end{array}$ & $\begin{array}{c}1.1 \\
(110)\end{array}$ \\
\hline Length of a root $(\mathrm{mm})$ & $\begin{array}{c}9.0 \\
(100)\end{array}$ & $\begin{array}{c}20.2 \\
(222)\end{array}$ & $\begin{array}{c}17.6 \\
(196)\end{array}$ & $\begin{array}{c}18.0 \\
(200)\end{array}$ & $\begin{array}{c}26.3 \\
(292)\end{array}$ & $\begin{array}{l}13.5 \\
(150)\end{array}$ \\
\hline Number of sprouts & $\begin{array}{c}3.9 \\
(100)\end{array}$ & $\begin{array}{l}3.7 \\
(95)\end{array}$ & $\begin{array}{c}4.5 \\
(115)\end{array}$ & $\begin{array}{c}3.9 \\
(100)\end{array}$ & $\begin{array}{l}3.6 \\
(92)\end{array}$ & $\begin{array}{c}4.8 \\
(123)\end{array}$ \\
\hline Length of a sprout (mm) & $\begin{array}{l}11.9 \\
(100)\end{array}$ & $\begin{array}{l}13.5 \\
(113)\end{array}$ & $\begin{array}{l}13.4 \\
(113)\end{array}$ & $\begin{array}{c}13.9 \\
(117)\end{array}$ & $\begin{array}{l}14.5 \\
(122)\end{array}$ & $\begin{array}{l}10.9 \\
(92)\end{array}$ \\
\hline
\end{tabular}

at the different intervals. New roots increase and elongate more in test samples than in controls, but no difference is seen in sprouts (Fig. 1).

B) The effect of applied E.M.F. in different direction on the root formation. As denoted in the following table new roots increase and elongate more in samples of basal+ direction than the opposite, but sprouts do not show any difference between them.

\begin{tabular}{|c|c|c|c|c|c|}
\hline \multirow[t]{2}{*}{ Treatment } & \multirow[t]{2}{*}{ Control } & \multicolumn{2}{|c|}{$\begin{array}{c}\text { Applied potential } 60 \mathrm{~V} \\
0.12 \sim 0.13 \mathrm{~mA} / \mathrm{cm}^{2} \\
\text { during } 30 \mathrm{sec} .\end{array}$} & \multicolumn{2}{|c|}{$\begin{array}{l}\text { Applied potential } 100 \mathrm{~V} \\
0.20 \sim 0.21 \mathrm{~mA} / \mathrm{cm}^{2}, \\
\text { during } 30 \mathrm{sec} .\end{array}$} \\
\hline & & Basalt & Basal - & Basal+ & Basal - \\
\hline Number of new roots & 2.2 & 4.3 & 2.6 & 4.1 & 2.2 \\
\hline Length of a root $(\mathrm{mm})$ & 15.8 & 22.7 & 15.3 & 17.3 & 8.1 \\
\hline Number of sprouts & 2.8 & 3.4 & 3.6 & 3.3 & 3.4 \\
\hline Length of a sprout ( $\mathrm{mm})$ & 8.7 & 9.7 & 10.5 & 10.8 & 9.7 \\
\hline
\end{tabular}

C) Transport of the root-forming substance and the effect of electric stimulus on it. The cuttings, $29 \mathrm{~cm}$ in length, were electrified with D.C. 100V, 
$0.54 \mathrm{~mA} / \mathrm{cm}^{2}$ during $30 \mathrm{sec}$. Then each stem was cut in two at the middle of it 1 minute, 1 hour and 60 hours after stimulation. The number of adventive roots, sprouts, and the length of a root and sprout are denoted in Fig. 2.
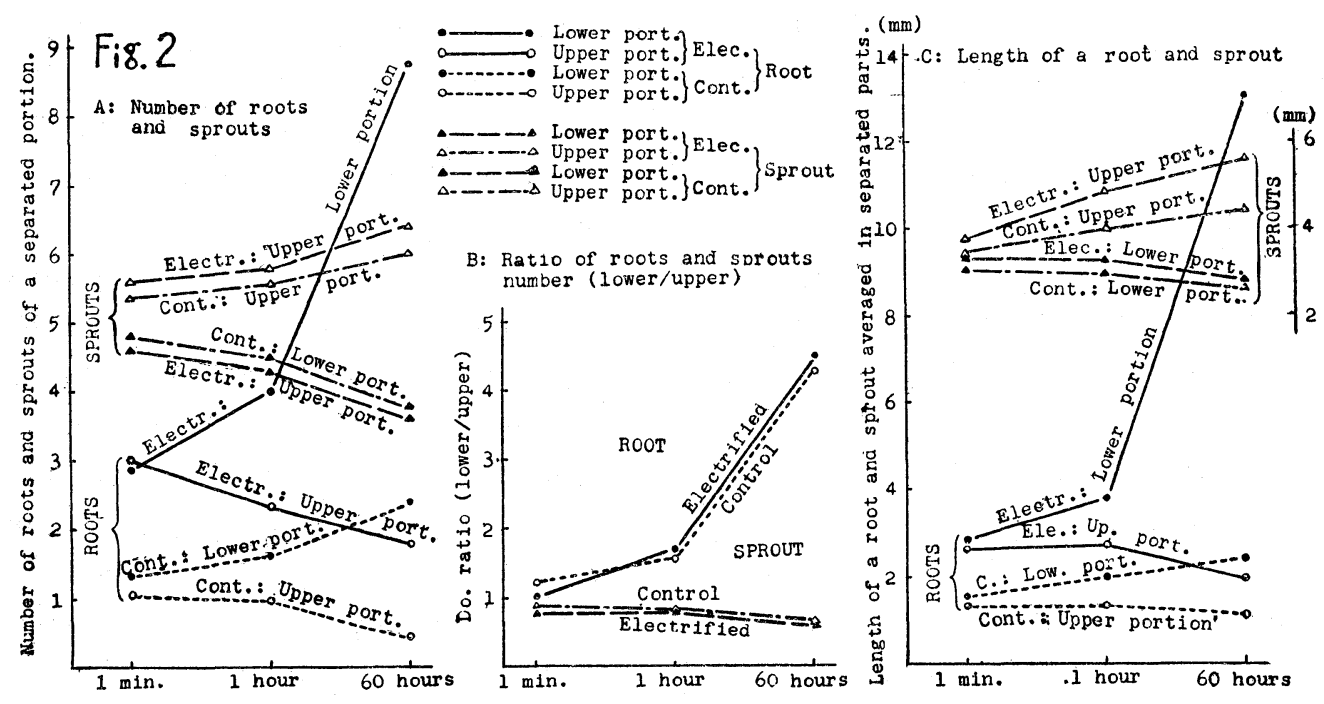

As already observed in other experiments, the results of electrifying show that the rooting and growth of roots are in all cases better than those of control, but sprouting does not show any remarkable difference between the test samples and the controls (Fig. 2). Intervals between electrifying and halving of stems are the period when the distribution of hormone becomes less in the upper part and more in the lower part, if downward transport of hormone takes place. The difference of rooting between the upper and lower parts of the stem affirms the above assumption (Fig. 2. A, B). This tendency is recognizable both in test samples and in controls (Fig. 2. A). The rooting ratio of the lower portion to the upper portion becomes larger in proportion to the length of the interval, but the ratio does not differ between the test samples and the controls at the same length of periods (Fig. 2. B). This fact proves that the hormone transport takes place in the controls as well as in the test samples.

D) The relation between the length of cuttings and the number of adventive roots. Cuttings of different length were placed in the dark. The result is as follows :

\begin{tabular}{lrrrrl} 
Length of a cutting $(\mathrm{cm})$ & 25 & 22 & 19 & 16 & 13 \\
\hline Num. of new roots $/$ Individual & 12.9 & 11.4 & 9.7 & 8.3 & 6.8 \\
Num. of new roots $/ 3 \mathrm{~cm}$ of stem & 1.56 & 1.56 & 1.53 & 1.56 & 1.56
\end{tabular}

The stems of $29 \mathrm{~cm}$ long had $8 \sim 11$ nodes and the average was just 10, each stem part of $3 \mathrm{~cm}$ having one node. So that, in the above table, as the unit of length 
$3 \mathrm{~cm}$ was taken. From this experiment it was known that the amount of new roots in the cuttings of $13 \sim 25 \mathrm{~cm}$ long is proportional to the length of the cuttings.

\section{DISCUSSION}

When the electric circuit in the glass cylinder filled with water is closed, its resistarce is $35.7 \mathrm{~K} \Omega(100 \mathrm{~V} / 2.8 \mathrm{~mA})$. But when the cuttings are immersed in the water its resistance lessens to $28.5 \mathrm{~K} \Omega$. If this decrease of resistance is due to the change of nature of water in the cylinder, this value will be kept after the samples are taken out. When the cuttings are taken out of water the resistance ascends to $34.4 \mathrm{~K} \Omega$ which is very near to the initial. This fact proves that the Salix cuttings have more conductivity than water. This agrees with Cholodny and Sankewitsch (3), though not with Koch (11). Therefore this apparatus is available to examine the effect of current through the plant body. The present authors got similar results as Watanabe and Ito (20): i.e rooting is better when the current is on, and when it is plus at the base. Hartmann (9) does not recognize the electric polar transport of hormone in plant organ. The increase of growth caused by electricity is explained by Bonner (1) as the result of the activation of reserved growth hormone, and by Strugger (18) as cataphoresis of common cation. If auxin, which induces sprouting, is made by applied current to accumulate on the cut end of an electrified stem, the variation of sprouting ought to happen. But no variation was found (Fig. 1 \& Fig. 2. B). The fact that rooting is effected by heteroauxin, Cooper (6) assumes, is due to the accelerated transport of root-inducing-substance " $\mathrm{Rhi}$ zocaline" and not to auxin. If electric current influences the transport of rhizocaline like heteroauxin does, and if it has nothing to do with the transport of natural auxin, electric current, causing the acceleration of transport of rhizocaline, will stimulate rooting and not sprouting as shown in the experiments of the authors. Cooper's treatment of heteroauxin is limited to the basal part of cuttings, whereas the treatment of electric current is applied to the whole parts, so its acceleration effect on downward movement of rhizocaline may evenly remain in the plasm of the whole stem, although the rhizocaline amount contained in each part may change as time elapses. The authors affirmed that the rooting occurs proportionally to the body length in number, i.e. is proportional to the amount of root-inducing-substance in body parts. If in electrified test samples the downward transport of rhizocaline is more accelerated than the control, the potentiality of rooting may be stronger in any portion of the test ones than those of the control. This assumption has been proved by the experiments. There should not be any difference of rooting potentiality among the portions cut in the same length immediately after electrifying. Of the two portions of the same the length which were cut 1 hour after electrifying the lower portion has larger rooting potentiality than the upper portion. The difference of the potentiality of rooting between the two portions cut 60 hours after electrifying, is larger than that of the above two examples. These results can be explained 
easily if the downward transport of rhizocaline is proportional to the length of the period between electrifying and separation. This time relation to rooting potentiality is also recognized in the same manner in the control which has not been electrified. But the observed value of deviation of rooting is larger in the test samples than in the controls. This ascertains above assumption, and also shows that although the electrifying is done by the temporary current, its effect remains as an after effect on rhizocaline or on plasm. Besides electric current Watanabe and Ito applied $\alpha$-naphthalene acetic acid which also accelerated rooting, and if they were applied together they gave additional effect. The present authors think that their result may also be explained by Cooper's theory. The previous work by the present authors (8) on etiolation of Hydrilla shows that electric stimulus and heteroauxin give no effect on rooting. This result is not consistent with the present investigation, because the etiolated plant has no rhizocaline, which limits rooting of plants under the lightless condition.

\section{CONCLUSION}

The acceleration of rooting of Salix cuttings effected by temporary direct current may be reasonably explained by Cooper's rhizocaline theory which tells that the stimulation induces the speedy accumulation of root forming substance, rhizocaline, on the cut end. Electrifying and heteroauxin equally serve as stimulus on rooting but in their manners the former is different from the latter as follows: 1) Stimulation equally affects all portions of the plant body, and it remains as an after effect. 2) Electric stimulation is somewhat ruled by its polarity: the current from cut end to apex is more effective that the opposite.

\section{Literature cited}

1) Bonner. J.: Protoplasma 21: 406-423. 1934. 2) Brauner, L. and Bünning, E.: Ber. d. bot. Ges. 48 : 470-476. 1930. 3) Cholodny, N.G. \& Sankewitsch, E. Ch.: Plant Physiol. 12: 385408. 1937. 4) Clark, W. G.: Plant Physiol. 12: 737-754. 1937. 5) — : Plant Physiol. 13: 529-552. 1938. 6) Cooper, W.C.: Plant Physiol. 11: 779-793. 1936, 7) Dolk, H.E.: Diss. Utrecht. 1930. 8) Fukuda, Y., Takaoki, T. \& Fujita, T.: Jour. Sci. Hiroshima Univ., Series B. 2, 6 : 105-126. 1952. 9) Hartmann, H.: Beiträge Biol. Pfl ınzen 19: 287-333. 1932. 10) Kinoshita, S.: Bot. Mag. Tokyo. 63: 83-89. 1939. 11) Koch, K.: Planta 22:190-220. 1934. 12) Kögl, F.: Angew. Chem. 46: 469 473. 1933. 13) Kosuge, S.: Bot. Mag. Tokyo. 47: 589-601, 640 656. 1933. 14) Rehm, W.S.: Plant Physiol. 14: 359-363. 1939. 15) Schrank, A. R.: Jour. Cell \& Comp. Physiol. 31: 1-6. 1949. 16) — : Plant Physiol. 25: 583-593. 1950, 17) Shibata, K. \& Shibuzawa, M.: Jour. Inst. Electrical Engineers Japan. 52: 618-625. 1932. 18 Strugger, S.: Jahrb. wiss. Bot. 79 : 406-471. 1934. 19) Thimman, K. \& Went, F. W.: Proc. Akad. Wetensch. Amsterdam 37. 1935. 20) Watanabe, I. \& Ito, K.: Monthly Report of the Electr. Power Technic. Inst. Tokyo. 2: No. 2. 91-96. 21) Went, F. W.: Jahrb. wiss. Bot. 76: 528-557. 1932. 